\title{
Prospects for Economic Cooperation among Developing Countries
}

\section{Vincent Cable}

Economic cooperation among ldcs (ECDC) is one item on the UNCTAD agenda which normally passes with a minimum of fuss. Developed countries tend to have a bias in favour of measures which involve ldcs doing things to help themselves. The developing world, almost by definition, favours greater solidarity between its component parts. It is therefore a measure of the fractiousness of UNCTAD $V$ that the subject generated considerable ill feeling. The Group of 77 chose to emphasise those aspects of ECDC which called for greater support from Group B, either directly or through international agencies. Group B opposed moves which appeared to compromise the 'universality' principle of the UN. Eventually all agreed to a long and complex resolution which has been interpreted (by the select few who can understand it) as giving greater emphasis to ECDC within the UN system, and particularly within UNCTAD's work programme.

In this new preoccupation with ECDC there is a paradox which this article seeks to explain. On the one hand there is a long history of failure of economic integration schemes between ldcs. Some have flourished briefly and amid much publicity, later to collapse. Others have advanced more cautiously, only for caution to lead to inaction. Yet as the more orthodox market integration arrangements have been rejected as inappropriate, and more unorthodox sectoral agreements have struggled to make any sort of practical progress, enthusiasm for ECDC has risen. ECDC was included in the NIEO programme adopted at the Sixth Special Session, and in the Manila Declaration. The Trade and Development Board of UNCTAD has established a committee on ECDC. The Group of 77 held a major conference on the subject in 1976, in Mexico. It featured prominently in the Arusha Programme for 'collective self-reliance' (in February 1979). This meeting also adopted a 'Short Term Action Plan for Global Priorities' on ECDC. And thence to UNCTAD.

\section{ECDC and Collective Self-reliance}

One major reason for the renewed enthusiasm now being expressed for ECDC is that is gives concrete expression to the otherwise somewhat woolly notion of collective self-reliance (CSR). Ldcs have been at pains to point out that CSR does not mean autarchy; it does not seek to build a wall of containment that seals off the developing countries from the outside world' (UNCTAD 1977). Rather, it is a combination of selective measures to promote economic cooperation among ldcs, and to strengthen their bargaining capability vis-à-vis the rest of the world. The experience of the ASEAN group shows how these can be combined. The group was originally formed for reasons not connected with UNCTAD North-South politics (rather as an expression of anti-communist CSR!). But it has made advances in practical measures of economic cooperation. It has also proved to have some value in trade policy negotiations. In its recent dealings with the EEC, Australia and Japan, ASEAN has impressed its opposite numbers, through threats of collective retaliatory action, as being altogether more substantial than the sum of its parts. The Andean Group, despite the amputation of Chile, has otherwise held together and, with ASEAN, is the most successful of the surviving arrangements. Its common policy towards foreign investment (Decision 24) has been weakened but its continued existence does give the Group's members greater bargaining power in dealing with companies seeking to play off one member against another. These are modest beginnings but they give developing countries a sense of the potential of ECDC in realising CSR.

Another factor is that whatever the success of particular integration schemes, there has been a substantial advance in inter-ldc trade. Manufactured exports from Idcs to other ldcs (over a 20 year period to 1976) 'not only grew faster than their total imports but also recorded similar growth rates to their total manufactured exports' (UNCTAD 1978). Inter-ldc trade as a proportion of ldc exports of manufactures had actually increased from 20 per cent in 1960-61 to 24 per cent in 1974-75. Inter-ldc trade as a whole in the 1970-76 period rose by 9.2 per cent annually in quantum terms (after 6.5 per cent in the 1960-70 period) as compared with 6 per cent for trade between developed countries and 5.8 per cent for exports from the developing to the developed world. 
Of manufacturing inter-ldc trade, totalling $\$ 14.8$ bn in 1976, $\$ 9$ bn originated in South and South East Asia, \$3.1 bn in Latin America and only $\$ 0.9$ bn in sub-Saharan Africa. Significantly, a major part of inter-ldc trade by volume has been within Asia in the absence of any formal regional grouping, while the growth in Latin American trade has mainly concerned Brazil, Argentina and Mexico whose regional exports have derived only modest encouragement from the largest Latin American integration scheme, LAFTA. Another area of major expansion has been the growth of ldc manufactured exports (mainly Asian) to the Middle East. This had grown from $\$ 0.2$ bn in 1970 to $\$ 1.1$ bn in 1975 and has greatly expanded since, with a good many orders for big capital project work still in the pipeline. In the case of India, for example, a combination of capital goods exports to the Middle East and workers' remittances from the region has offset much of the cost of oil price increases and done far more to maintain Indian support for Arab causes than any amount of political posturing or diplomatic manoeuvring.

The significance of this recent experience of inter-ldc trade for the future of ECDC is considerable. Ldc exporters have already acquired a widening range of commercial contacts, familiarity with trading procedures, goodwill and servicing capacity, whose absence hitherto acted as a barrier to entry and favoured established, developed country, traders. The existence of this inter-ldc trade base should make easier any future attempts to integrate the ldcs' economies more closely through trade policy measures. It also suggests much wider possibilities than those represented by the restricted membership of the present regional integration groups.

Finally, there has been a deterioration in the prospects for exports to industrialised countries. Reduced growth in OECD markets and evidence of increased protectionism have begun to undermine the more optimistic assumptions which underlay economic strategies based on exports, particularly of manufactures, to these countries. It is far too soon to say that assumptions and policies now need to be completely revised but even the most outward-looking ldcs may now be inclined to shift, at the margin, towards import substitution. Import substitution at a multinational rather than a national level helps to reduce the cost of producing scale-sensitive capital and intermediate goods. Advocates of ECDC also claim that 'by providing markets for each other's products developing countries will ease the burden of adjustment in developed countries and make them more amenable towards less restrictive policies' (UN 1979). The reason why industrialised countries should welcome adjustment problems in their export industries (which is what ECDC would entail) while resisting them in their import competing industries is obscure. However, welcome or not, the developed countries are ill-placed to prevent such third market competition.

The rationale for greater emphasis on ECDC appears well founded. The question then is what can be done to promote it. A good place to start is by looking at the role of the existing arrangements.

\section{Market Integration Approach to ECDC}

A great deal of critical ink has been spilt in analysis of those ldc regional integration agreements which were based on regional free trade. ${ }^{1}$ The traditional trade liberalisation, or market integration, approach has been tried most recently in East Africa, Central America, the Caribbean (CARICOM), and former French West' Africa (UDEAC). It also forms a major ingredient in the Andean and (to a lesser extent) ASEAN schemes. The traditional approach derived its inspiration from several sources: the success of trade liberalisation in Western Europe: theoretical reasoning, based on assumptions mainly applicable to industrialised countries, which pointed to the potential economic efficiency gains (in static and dynamic terms) from regional trade liberalisation; and the institutional framework under GATT, which facilitated customs unions but not partial preferential tariff cutting.

The evidence has pointed (indeed most of this was already clear before 1970) to some negative conclusions:

- the impact of the schemes upon the acceleration of growth has been modest. Some would say it has been 'minimal' and 'its effect upon the general welfare.... has on the whole been negative' (Wionczek 1978);

-liberalisation was accompanied by a polarisation of economic gains and losses, with the larger and more advanced countries benefiting disproportionately, despite attempts to apply corrective measures;

1 There is an excellent survey of the literature in Vaitsos (1978) and in comments by Robson and Wionczek (both 1978), atso in Salgado (1978). 
- the major beneficiaries of regional trade liberalisation have often been large foreignbased firms.

Vaitsos (1978) concludes on the basis of this experience that integration should not, in most cases pursue holistic strategies, but should concentrate on specifically identified areas or projects'.

It does seem, however, that these conclusions are too stark and negative. In those schemes which still function tolerably well (such as the Andean Group), trade liberalisation has done far more to raise the level of regional trade than any other instrument and has not in practice proved a major source of friction. Colombia has appeared to benefit disproportionately but Chile left the group for other reasons, notably over differences concerning foreign investment rules and the height of the external tariff. The polarisation of costs and benefits in market integration schemes is well documented. But it was not the main cause for the breakdown of the Central American Common Market (though it was a convenient rationalisation of difficulties which occurred after the 'football war'). Fundamental political differences between the East African Community governments (and, earlier, in Malaya and Central Africa) contributed far more to disintegration than the regional balance of gain and loss (Malaya and Singapore now work apparently harmoniously in ASEAN, where they have common political objectives, despite the fact that Singapore appears to gain most economically from the arrangement just as it did in the illfated Malayan federation). It is an inconvenient fact to have to acknowledge for those whose job it is to promote unity amongst developing countries, that the hostility between many neighbouring ldcs is so profound that no conceivable regional cooperation arrangement could ever work. For this reason it is almost pointless to discuss serious economic integration in the Indian subcontinent, and in most of the Middle East.

The other, positive, side of the argument is that the traditional integration arrangements did produce net gains for their members while they lasted. The work done by the present writer, among others, on Central America supports this conclusion (Cable 1973). It may be that integration failed to generate wider structural changes but that was because the basic development strategy was misconceived. Import substituting industrialisation, pursued by the same governments with the same goals but at extra cost within national rather than subregional boundaries, is worse. Another danger of categorically rejecting the market integration approach is that there may be areas of the world (such as South East Asia) where this is likely to be a congenial form of economic cooperation both for political reasons and because there are economies with sufficiently robust industrial sectors which can absorb a certain amount of competition. Moreover where there is a genuine commitment to integration there are well understood mechanisms-fiscal compensation, partial non-reciprocity, use of import safeguard measures -to prevent trade liberalisation becoming seriously disruptive. Nonetheless, despite these positive factors, there is little doubt that regional trade liberalisation can only be one part of the package.

\section{The Sectoral Approach to ECDC}

Out of disillusion with pure customs unions theory applied to ldcs, there has emerged a modified theory, and practice, based on the planned development of regional industries. The theory is based on the proposition that regional integration can lower the cost of industrial import substitution where economies of scale are substantial. With the help of planning models it is possible to demonstrate the magnitude and distribution of these savings and a good deal of work has been done to adapt mathematical models to particular integration problems. ${ }^{2}$ Other work has shown how the solutions to particular industrial allocation problems can be combined for different industries to produce optimal solutions, subject to given distributional constraints (Nugent 1975). It follows from the approach that the main objective of regional integration schemes is to isolate the scale-sensitive industries which benefit from rationalisation at a regional level and to try to allocate new investment in a way that produces significant savings but gives all participating members a worthwhile stake. The concept of sectoral planning thus combines a plausible theory with the politically attractive feature that nervous and nationalistic governments can have close control over the outcome. It also appeals to economists who have not yet despaired of sowing the seed of dirigiste economic planning in otherwise infertile market cconomies. For these reasons sectoral agreements have come to play a prominent role in the currently most successful integration schemes, the Andean and ASEAN groups.

\footnotetext{
2 The most relevant of these are summarised in Robson (1978), and applied in Cable (1973).
} 
It has proved extremely difficult, however, to translate sectoral integration programmes from the abstract to the concrete. Although it is now fashionable to write off the Central American and East African experiments as having failed because of the damaging 'backwash' effects of market integration, both incorporated sectoral planning mechanisms which proved extremely difficult to operate. Within the Andean group, after over five years of negotiation, only three of the eight proposed sectoral agreements have been signed. One of these, petrochemicals, largely rationalises an obvious locational distribution based on Venezuelan feedstock. The third, automobiles, is still subject to considerable disagreement. ASEAN industry programmes have also made very slow progress. In both cases interregional trade in the products of 'regional industries' is a miniscule proportion of the total.

It is not adequate to regard these as teething difficulties which can be overcome with a little encouragement from UNCTAD. Those, like the author, who have spent years experimenting with spatial and inter-temporal sectoral planning models for regional integration schemes have to ask themselves why their work has proved so difficult to put into practice. One reason is that it is naive to expect governments so suspicious of their neighbours as to be unable to arrive at arrangements for dealing with imbalances in overall, inter-regional trade, suddenly to be transformed into rational, cooperative planners when they are dealing with particular industries.

On the contrary, experience shows that the politicisation of every industrial allocation decision increases rather than decreases the scope for disagreement and misunderstanding. Although suspicion and resentment should in principle be less when the trade outcomes can be predicted and quantified, outcomes cannot in practice be so easily predetermined. Planners and politicians can allocate a car plant to Bolivia or a chemical plant to Indonesia but they cannot easily force a private company to go there. Nor can the technology automatically be bought by governments off the shelf to undermine a recalcitrant private enterprise or fill a regional allocation more quickly. The appalling problems faced, for example, by Venezuela in getting its petrochemical complex, El Tablazo, to function at all should be a salutory warning to those who believe that the main problem is to get the investment location and timing decisions right whilst the entrepreneurial and technical problems will solve themselves. Further, none of the existing schemes have proved an effective check on governments which, with the backing of private investors, wish to set up plants in defiance of regional allocations (other than through the possibly irrelevant sanction of denial of access to the regional market).

It is of course easy to pick holes in ambitious experiments, actual or envisaged. Even an arbitary and industrially illogical regional allocation of industries may well prove less inefficient than the competitive duplication of protected plants conceived in each country independently. Moreover if economic integration has to be approached cautiously for political reasons, the sectoral approach may be the best way to start. Nor are specific projects to be confined only to industries. Some of the most fruitful sources of potential economies of scale he elsewhere, in building up universities or airlines or in transport planning. These also depend much less on the compliance of foreign firms. But the track record of cooperation in these fields is not impressive either.

\section{New Approaches to ECDC}

ECDC achieved through regional integration schemes of the kind previously experienced promises to be a long and difficult business. For this reason, there is value in looking at other approaches, some of which UNCTAD and other agencies are now trying to highlight (UNCTAD 1976, 1976a and 1977). We consider some examples below.

\section{Managed complementarity}

Both the orthodox (trade liberahising), and the sectoral planning approach to integration focus upon those elements-mainly manufacturing-in ldc economies, which are actually or potentially competitive. Though the means are very different, the end is the same; greater economic efficiency and the income gains which flow therefrom. But there are potential efficiency gains other than complementary economic links between capital- and resource-rich developing countries, and labour- (and skill-) abundant countries. Inter-ldc trade already reffects this in part. In 1975 , of the $\$ 47$ bn of inter-ldc trade, $\$ 10$ bn was in food and agricultural raw materials and $\$ 22$ bn in fuel; in 1970 , before oil prices inflated fuel values, the contribution made to the total value of inter-ldc trade ( $\$ 11 \mathrm{bn}$ ) was $\$ 3.7 \mathrm{bn}$ by fuel and $\$ 3.3$ bn by other raw materials. Some of the most important recent manifestations of economic cooperation between developing countries have come from the growing trade and factor movements between OPEC and non-oil ldcs. Some of these relations are governed by a 
modified form of bilateral barter; eg. the deals reached by Petrobras of Brazil for Middle East oil in return for exports of capital goods (and arms), or for Venezuelan oil in return for nuclear technology. The rapidly developing commercial diplomacy between India and Iran (at least under the Shah) covered larger-scale iron ore sales as well as oil. More complex arrangements have been envisaged in the Caribbean and the Middle East for building up aluminium industries based on complementary ldc contributions of bauxite, finance, labour and cheap power. This (ex ante) complementarity of interest has also been one of the less publicised (and sometimes less politically popular) aspects of cooperation in the Andean Group, within which Venezuela draws extensively upon Colombian migrant labour and uses its oil wealth to try to establish a regional comparative advantage in capital intensive, energy based industry. Of course, bland talk about 'cooperation' and 'complementarity' should not obscure the underlying reality of non-oil ldcs searching for means of paying more for their oil. The unequal distribution of gains from ECDC is still with us, but in a different guise.

\section{Global preferences}

One of the main features of the ECDC strategy mapped out by UNCTAD is a system of trade preferences between ldcs on a global scale but without a commitment to full trade liberalisation. The main rationale behind this idea is that the regional schemes, whatever their advantages, have the effect of diverting trade from other ldcs and fostering trade within regions rather than trade between ldc regions. It has considerable unexploited potential, particularly for products for which transport costs are not high in relation to unit value. Moreover some of the more industrialised ldcs are currently outside functioning regional groups (India, Korea, Yugoslavia, Egypt) or else are involved in groups which are making little headway (the LAFTA members: Mexico, Brazil and Argentina). Global preferences have a particular potential because ldcs which are at a similar, relatively advanced, stage of industrialisation have less to fear from the polarisation of industrial development which has been one of the most inhibiting features of regional trade between neighbouring countries at unequal levels of industrial attainment. There has already been some modest progress. Sixteen developing countries, mainly NICs, together with Spain and Greece, negotiated a 1971 protocol under GATT auspices which gave effect to multilateral tariff cuts on 500 items. Trade in these products amounted to $\$ 138 \mathrm{mn}$ in 1976 , a tiny sum, but 250 per cent higher than three years earlier when the scheme came into effect.

Yet it would be unwise to pin too many hopes on rapid advance. The same reserve which holds back NICs, such as Korea and Brazil, from offering a greater degree of reciprocity in trade negotiations with industrialised economies operates also in their dealings with competing countries at a similar level of development. The production of consumer goods is usually heavily protected either by prohibitive tariffs or a combination of tariffs and quotas. In some cases this makes eminently good developmental sense. It is difficult for example to see any good reason why India should open up its protected village industries, making shoes and cloth, to competition with the products of Korean or for that matter Bangladeshi factories. Quite apart from the political problems of countries that are still relatively poor facing trade adjustment problems of a magnitude which even the richest countries are reluctant to contemplate, there are substantial technical difficulties in the way of negotiating reciprocal concessions when the degree of protection is very large but cannot easily be measured. A different problem exists with capital goods which are usually lightly protected. The degree of preference margin which can be offered is small and of dubious value since capital goods trade is generally not very price sensitive.

The greater the spread of countries involved in negotiations (in terms of levels of industrialisation) the greater the problems, as regional schemes have already demonstrated. A preference scheme involving all, or at least the most important, ldcs is likely to encounter problems which would make those of regional schemes look petty by comparison. But its prospects for success would be greatly enhanced if, first, tariff and non-tariff barriers were included, and second, if agriculture and other raw materials could be incorporated into the 'trade-offs' amongst regional members in order to realise the benefits of natural complementarities. After all, Western European integration developed rather less through politicians seeing the potential gains from industrial 'trade creation' than from what they saw as the complementarity of interest between German industry and French agriculture. Amongst ldcs, common ground could be found by exchanging trade preferences for special terms in the purchase of raw materials or for trading quotas under commodity agreements. Finally, a preference scheme would 
be more likely to succeed if negotiation was mainly confined to the dozen or so major NICs with serious manufacturing interests. If a gesture were to be made to the others it could most usefully be in the form of granting to the least developed' preferential access on a non-reciprocal basis. Attempts to involve most of the $100+$ developing countries in serious trade negotiations would simply be unmanageable.

\section{Trade supporting measures}

Preferential trade concessions, even if agreed, are likely to be of modest overall importance in stimulating inter-ldc trade in relation to factors such as the development of shipping routes, greater familiarity with new markets, improved export credit and clearing facilities. Not all the present deficiencies are amenable to treatment, at least in the short term. But something could be done, for example, to help equalise terms on which ldcs have to compete in the supply of capital goods. Most industrialised countries have the advantage of being able to offer long term export credits and guarantees, of ten at below market rates, and also tied aid. One reason for the success of ldc capital goods exporters in the richer oil states is that their clients will pay cash, but this is not the case elsewhere. The establishment of a competitive export credit machinery is partly a question of expertise but mainly one of resources.

Another difficulty arises from exchange control and the reluctance of surplus countries to accept settlement in non-convertible currencies. Bilateral barter can dispose of this difficulty but it is clumsy and constricting. Recognising the problem, the Pearson Commission recommended a multilateral clearing system between ldcs. Nothing has since been done globally but most regional common markets have devised methods of handling short term imbalances, and some have evolved mini-IMFs to provide medium term credit to bridge longer and larger imbalances. The larger the resources available, the greater the scope for such arrangements; the Arab Monetary Fund, predictably, is the most ambitious at present.

Most UNCTAD documents have given prominence to the role which might be played in inter-ldc trade by state trading corporations, and government-to-government contracts. These are almost certainly likely to be less important than Idc (privately owned) TNCs and private traders. Because much of the literature on economic integration has been about Latin America and not about Asia it has tended to underestimate the resilience of developing country entrepreneurs and to exaggerate the dangers of greater interIdc trade being monopolised by Western companies. One of the most useful supporting measures which might be taken in support of ECDC would be some liberalisation of inter-ldc long term capital movements. The Indian Government has taken steps recently to promote Indian foreign investment through joint ventures overseas and this follows an already significant, and productive, involvement by Indian firms in Africa and South East Asia.

\section{Institutions and ECDC}

Current controversies over ECDC have little to do with the relative efficacy of various methods of promoting closer economic integration between developing country economies. The main debate has been about institutional arrangements for furthering ECDC. Should there be a separate 'Third World Secretariat' apart from UNCTAD? Should developed countries be asked to fund projects designed to promote CSR, and if so, what kind of voice should they be allowed in decision making? Behind the procedural questions there is a fundamental difference of approach. From one point of view, ECDC can be seen simply as an exercise in closer regional economic integration between developing countries. This is scarcely new or controversial, and most developed countries would happily support it. The EEC, in search of kindred spirits, has consciously tried to organise its external relations around groups such as ASEAN, the Andean Group and the Central American Common Market. Diplomatic support has been reinforced by small but helpful gestures of a more tangible kind, such as the treatment of inter-regional trade as of cumulative origin under rules of origin requirements for trade preferences. A great deal more help could reasonably be solicited from the Western institutions-financial and technical assistance for export credit institutions and for the regional monetary funds; a much wider definition of cumulative origin under GSP schemes; a relaxation of bilateral aid-tying to permit ldcs to purchase capital goods from each other. But, as most ldcs recognise, the bulk of the effort they must make themselves.

From other points of view, ECDC takes on a different character, and particularly if the objective of welding developing countries into a much tougher and more coherent negotiating unit is emphasised. Whilst the Group of 77 machinery has served as a unifying force in UN meetings (where little of real substance is decided) the negotiating front of the ldcs has often crumbled 
under pressure in difficult 'bread and butter' negotiations, as on textile quotas. By contrast the success of OPEC, despite internal differences, in maintaining effective control over world oil supplies serves as a model of what can be achieved when circumstances are more favourable. Those who argue for a Third World Secretariat believe that ldcs need a body which can coordinate tactics, and provide detailed briefing for technical negotiations with the North, in which ldcs have a strong interest. The nearest approach to such a body at present is SELA (Latin American Economic Systems) which was set up to provide this kind of support for Latin American countries, though it is difficult to see what in practice it has achieved so far. It is understandable, given these aims, that ldes should wish to organise independently of developed countries. But it is equally understandable that industrialised countries are unlikely to dig into their pockets to assist a body working directly contrary to their interests, and are concerned about the UN being used as a vehicle for this purpose.

It is in many ways a pity that these two aspects of ECDC have not been separated. It is of course true that closer integration can lead to greater coherence in dealing with third parties; this has been the experience of the EEC and more recently of ASEAN. But it is not a necessary consequence, and the most effective example of ldc producer organisation has been between countries with nothing in common beyond a (sometimes wavering) commitment to restrain their export of oil. There is a great danger, if the issues are confused, that the very difficult, long term task of achieving closer economic integration between developing countries will be submerged in the necessary but different process of organising the South to negotiate more effectively with the North.

\section{References}

Cable, V., 1973, 'Economic Integration and the Industrialisation of Small Developing Nations: the case of Central America', unpub. PhD thesis, University of Glasgow

Nugent, J. B., 1975, 'The Selection of Industries for Regional Coordination among Developing Countries, Journal of Common Market Studies, vol. 14 no. 2

Robson, P., 1978, Comments on Vaitsos, World Development, vol. 6, June

Salgado, G., 1978, Viable Integration and the Economic Cooperation: Problems of the Developing World, UN Committee for Development Planning, New York

UN, 1979, Issues Before UNCTAD V, Press Release, (TAD/INF/1032), New York

UNCTAD, 1976, Economic Cooperation among Developing Countries, (TD/192), Geneva

-1976a, Report of the Conference on Economic Cooperation among Developing Countries, (77/COOP/CMEX/12), Geneva

-1977, New Directions and New Structures for Trade and Development, TD/183/Rev. 1), Geneva

-1978, Trade among Developing Countries by Main SITC and by Regions, (TD/B/C-7/21)

Vaitsos, C. V., 1978, 'Crisis in Regional Economic Cooperation (Integration) among Developing Countries', World Development, vol. 6, June

Wionczek, M., 1978, Comments on Vaitsos, World Development, vol. 6, June 